\title{
Intraoperative mobile magnetic resonance imaging for craniotomy lengthens the procedure but does not increase morbidity
}

\author{
[Un appareil mobile d'imagerie par résonance magnétique utilisé pendant la \\ craniotomie prolonge l'opération mais n'augmente pas la morbidité]
}

David P. Archer MD, ${ }^{*}$ Robert A. McTaggart Cowan MD, ${ }^{*}$ Richard J. Falkenstein MD, ${ }^{*}$ Garnette R. Sutherland MD†

Purpose: To evaluate anesthetic aspects of care provided for craniotomy using mobile intraoperative magnetic resonance imaging (iMRI).

Methods: Anesthetic factors were studied using a retrospective case-control design. The primary outcome measures were the duration of the surgical intervention; the recovery score and body temperature on arrival; and length of stay in the post-anesthetic care unit. Secondary outcome measures were estimated blood loss, perioperative transfusion requirements, and fluids administered.

Results: Seventy-six patients undergoing craniotomy in the MRI theatre were compared with a case-matched control group of patients who underwent neurosurgical interventions in the conventional operating room during the same time period. The only outcome measure that differed between the two groups of patients was the duration of surgery: the mean duration of procedures for patients who underwent imaging was $407 \pm 143$ min compared to $285 \pm 122 \mathrm{~min}$ in the conventional operating theatre $(P<0.000)$. Actual time spent imaging accounted for approximately $100 \mathrm{~min}$ (83\%) of the increased duration.

Conclusion: Our results do not support concerns that the iMRI suite is a "hostile" environment for the delivery of anesthesia for craniotomy. With the exception of an increased duration of the procedure, patients undergoing anesthesia with iMRI showed no differences from those operated in the conventional operating theatres.

Objectif : Évaluer les aspects anesthésiques d'une craniotomie comportant l'utilisation d'un appareil mobile d'imagerie par résonance magnétique peropératoire (IRMp)
Méthode : Les facteurs anesthésiques ont été étudiés selon une méthode de cas-témoins rétrospective. Les principaux résultats mesurés ont été la durée de l'intervention chirurgicale, la cotation de la récupération et la température corporelle à l'arrivée ainsi que la durée du séjour en salle de réveil. Les résultats secondaires ont été la perte sanguine estimée, les besoins de transfusion périopératoire et les liquides administrés.

Résultats : Soixante-seize patients devant subir une craniotomie dans une salle d'IRM ont été comparés à un groupe de cas témoins appariés qui devaient subir des interventions neurochirurgicales dans des salles d'opération traditionnelles pendant la même période. Le seul résultat intergroupe différent a été la durée de l'opération : la durée moyenne pour les patients d'imagerie a été de $407 \pm 143$ min comparée à $285 \pm 122 \mathrm{~min}$ dans la salle habituelle $(P<0,000)$. Le temps réel accordé à l'imagerie a été d'environ 100 min (83\%) de la durée accrue.

Conclusion : Nos résultats ne s'accordent pas avec l'idée qui veut que la salle d'IRMp constitue un environnement «hostile» à l'anesthésie pour la craniotomie. Mis à part la durée accrue de l'intervention, les patients qui ont eu une anesthésie sous IRMp n'ont montré aucune différence avec ceux qui ont été opérés dans une salle traditionnelle.

From the Departments of Anesthesiology* and Neurosurgery, $\nmid$ Faculty of Medicine, The University of Calgary, Calgary, Alberta, Canada. Address correspondence to: Dr. David P. Archer, Department of Anesthesia, Foothills Medical Centre, $1403-29^{\text {th }}$ Street NW, Calgary,

Alberta T2N 2T9, Canada. Phone: 403-670-1667; Fax: 403-670-2425; E-mail: david.archer@CalgaryHealthRegion.ca

Supported, in part, by the Medical Research and National Research Councils of Canada. Presented, in part, at the Annual Meeting of the American Society of Anesthesiologists, San Francisco, CA, USA, October 2000.

Accepted for publication November 13, 2001.

Revision accepted January 16, 2002. 
developed a mobile high field magnetic resonance imaging (MRI) system. ${ }^{1-4}$ This unique design allows the acquisition of high quality intraoperative MRI (iMRI) for intervention planning, surgical navigation and quality assurance without moving the patient. Introduction of this technology requires specific modifications to the operating room (OR) environment to ensure the safety of the patient and the OR personnel, to comply with current guidelines for anesthetic care, and to minimize the interference with imaging. ${ }^{5}$

The delivery of anesthesia for patients undergoing MRI has been described as "making new demands on the anesthesiologist", both with respect to the "hostile environment" $"$ and related to the problems with medical devices in the MRI environment. ${ }^{7}$ For surgery using iMRI to be operational, it is important to establish that the increased demands upon the anesthetic team do not translate into increased risk for the patient. The delivery of anesthetic services in the iMRI environment has been well established and described, but the additional burden of complex neurosurgical procedures in the latter environment has not been evaluated. Specifically, we wanted to evaluate the possibility that there would be a substantial increase in the duration of cases related to the time required for imaging, the unfamiliar environment of the iMRI OR and modifications in the surgical approach based upon intraoperative imaging. In addition to prolonging the procedure, additional surgery prompted by intraoperative imaging might lead to increased blood loss and increased fluid requirements. Since the recovery from both volatile and opioid anesthetics can be prolonged by increases in exposure to the drugs ${ }^{8,9}$ we speculated that increased duration of anesthesia time could lead to prolonged emergence times. In combination with the lack of continuous temperature monitoring, increased procedure duration might lead to mild hypothermia on emergence. Although we are unaware of any specific data relating these factors to postoperative wound infection in patients undergoing craniotomy, we were concerned that the latter might be the case, and hence determined the infection rate in both groups of patients.

In December 1997, the mobile 1.5 T iMRI system became operational. The multidisciplinary research team, composed of neurosurgeons, physicists, magnetic resonance (MR) technologists, nurses and anesthesiologists, developed a plan for the staged implementation of iMRI, including safety evaluations and continuous quality improvement.

As part of the evaluation, we conducted a retrospective case-control study to compare the anesthetic aspects of craniotomy performed in the iMRI theatre with similar procedures performed in the conventional operating suites at our institution. Here we report on the anesthetic aspects of management in the iMRI theatre during the first two years of operation. Neurosurgical, nursing and technological aspects of this device have been reported previously. ${ }^{1-4}$

\section{Materials and methods \\ Patients}

The University of Calgary Conjoint Health Research Board approved the study. The neurosurgery service at Foothills Medical Center, the referral centre for all adult neurosurgical patients in southern Alberta, Canada, performs 800-1000 elective or urgent craniotomies annually. Between December 1997 and December 1999, 80 patients underwent elective craniotomy using iMRI (iMRI group). The selection criterion for iMRI management was the presence of a lesion whose surgical removal could potentially benefit from iMRI on the basis of lesion localization and resection control (surgical planning and interdissection images), ensuring its complete resection and revealing the presence of complications (quality assurance image). Surgical exclusion criteria included contraindications to exposure to a high field magnet, and lesions requiring positions other than supine or lateral, which were not practical with the initial prototype magnet. The sole anesthetic exclusion criterion during this period was the presence of coronary artery disease that required segment (ST) monitoring of the electrocardiograph (ECG). These patients were excluded because the technical limitations of the MR compatible cable and restricted electrode placement preclude ST mapping. A control group was selected from the cohort of patients that underwent similar neurosurgical procedures in the conventional operating suite during the same time period (conventional OR group). One control patient was matched to each iMRI patient, based upon five criteria: lesion type (vascular vs tumour), lesion pathology obtained at surgery, lesion location (lobe and side) and lesion size on the preoperative MR or collimated tomography image (when available).

\section{Primary end points}

The primary end points were: duration of the procedure, the recovery score and body temperature on arrival in the postanesthetic care unit (PACU), and the length of stay in the PACU. The duration of the procedure was measured from the time that the first vital signs were recorded in the anesthetic record to the time of leaving the operating theatre. Recovery from anesthesia was evaluated by the PACU nursing staff based upon: airway maintenance, respiratory rate, skin colour, and level of consciousness, with two points 
being the optimal score for each criterion, thus generating a maximum score of 8 . Length of stay in PACU was measured from arrival until discharge or readiness to discharge as recorded in the PACU record. Treatment failure was defined as the requirement to limit the anesthetic or operative procedure because of technical problems involving the theatre.

\section{Secondary end points}

Secondary end points included estimated blood loss, intraoperative transfusion requirements and fluid administration, as determined from the anesthetic record. Characteristics of anesthetic management that were recorded included the position of surgery, drugs used for maintenance of anesthesia (opioids, volatile anesthetics, and nitrous oxide) and muscle relaxants.

\section{Data analysis}

Data sheets for the perioperative period were completed for each patient following review of the chart in the medical records department. Data were entered into a computerized spreadsheet for analysis (Excel® Microsoft Corp, USA). Quantitative data were analyzed by two-tailed t tests comparing the iMRI group with the conventional OR patients. Frequencies (e.g., use of isoflurane, opioids, muscle relaxants) were compared with contingency tables and subjected to the Chi square test. Statistical significance was inferred when $P<0.05$.

\section{Operative technique and $i M R I$ procedure}

The neurosurgical techniques and the mobile iMRI technology have been described in detail previously. ${ }^{1-3}$ Briefly, the iMRI technology at the University of Calgary uses a high field $(1.5 \mathrm{~T})$, mobile magnet to generate quality intraoperative images. Images are obtained intermittently during planned interruptions in surgery by moving the magnet over the patient (Figure). This enables the use of conventional surgical instruments, which are removed from the field during imaging. Equipment that remains in the field, including the head clamp, operating table, and the anesthetic and monitoring devices that are attached to the patient are MR compatible (are not influenced by the magnetic field and do not alter the MR image). In its initial design, the superconducting magnet had an internal free base diameter of $62 \mathrm{~cm}$, limiting the patient size to $100-110 \mathrm{~kg}$ and limiting imaging in the lateral and prone positions because of the width of the shoulders. The latest superconducting magnet, with an internal free base diameter of $72 \mathrm{~cm}$, permits imaging of patients up to $150 \mathrm{~kg}$ in all positions except sitting.

Since the MR theatre does not have a radiofrequency (RF) shield in the walls, ceiling and floor to eliminate interfering signals from the environment, local RF shielding was developed (Figure). Ports in the housing of the cage provide access to the patient during imaging. All connections of devices attached to the patient ventilator tubing, non-invasive blood pressure (NIBP) cuff, ECG, pulse oximeter, and all iv and pressure monitoring lines pass through $5 \mathrm{~cm}$ diameter, $75 \mathrm{~cm}$ long titanium tubes that provide additional RF shielding.

\section{Anesthetic equipment}

Selection criteria for each device used in the MR theatre were that 1 ) it not generate RF signals that would interfere with imaging (e.g., standard pulse oximeter); 2) there were no wires in which current induction during imaging would result in thermal injuries and $\mathrm{RF}$ interference.

The MRI compatible anesthetic machine used in the study was the Ohmeda Excel 210 MRI compatible (Datex Ohmeda, Helsinki, Finland). The patient monitor that was used was the Maglife ${ }^{\circledR}$ MRI monitoring system (GroupeBruker, Wissembourg, CEDEX, France), designed for use with MRI magnets up to $2 \mathrm{~T}$. The monitoring system uses optical arterial oxygen saturation $\left(\mathrm{SpO}_{2}\right)$ sensors, carbon fibre ECG electrodes, and incorporates high performance RF filters.

Variables measured in all patients included NIBP, $\mathrm{SpO}_{2}$, ECG and heart rate, end-tidal carbon dioxide $\left(\mathrm{ET}_{\mathrm{CO} 2}\right)$ and respiratory rate, inspired and expired oxygen concentrations and end-tidal concentrations of nitrous oxide and volatile anesthetics. Intermittent axillary temperature monitoring was available and two invasive pressure monitors were available for use when indicated.

\section{Results}

During the study period 79 patients underwent 80 operative procedures performed in the MR theatre. There were 280 procedures performed in the conventional OR during the same period that qualified for the matching process. Four iMRI procedures were excluded: a repeat procedure and three procedures for which no reasonable match could be found in the conventional $\mathrm{OR}$ database. The unmatched procedures included two hippocampectomies for epilepsy and one excision of a skull-base angiofibroma. The analysis was based on the 76 procedures in the MR theatre for which a matching case could be assigned.

\section{Quality of matching}

The demographic characteristics of the treatment groups is shown in Table I. The degree of lesion matching is shown in Table III. The majority $(71 / 76)$ of patients matched on at least $3 / 5$ of the match criteria. 

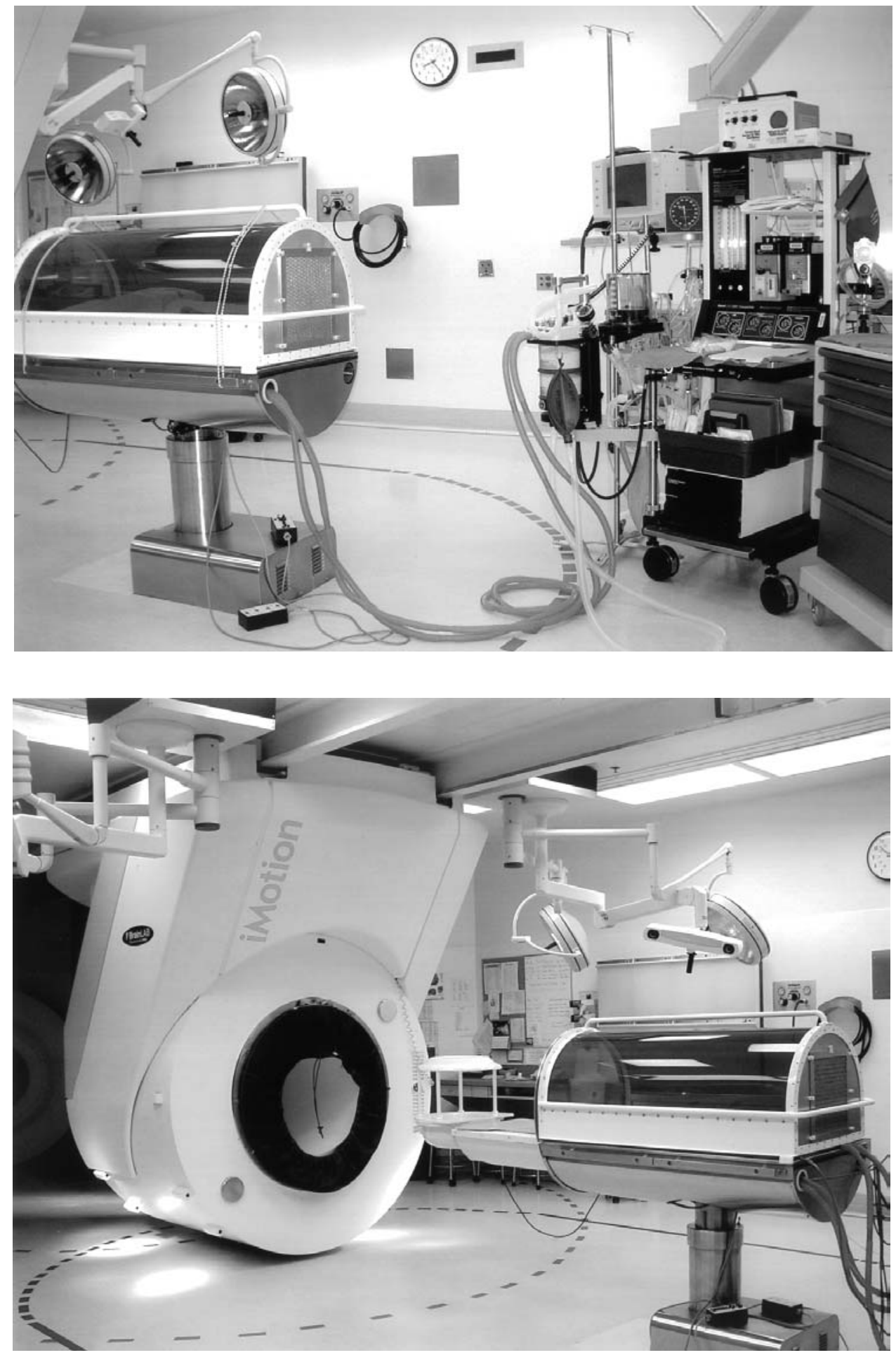

FIGURE Mobile intraoperative magnetic resonance imaging. A, The anesthesia machine, monitors, and anesthetic cart are located at the foot of the magnetic resonance compatible operating table, outside of the high fringe field region (marked on the floor with a dashed line). The white cage on the operating table is a radiofrequency (RF) shield covering the patient below the shoulders. Interference from signals associated with the anesthetic equipment is removed by passing all monitoring leads and ventilation tubing through RF shielding tubes built into the foot of the operating Table. B, For imaging, the magnet (suspended from the ceiling) is brought out of the shed to enclose the patient's head and upper chest. 
TABLE I Influence of iMRI on perioperative process outcome variables

\begin{tabular}{|c|c|c|c|}
\hline Variable & iMRI theatre & Conventional OR & $P$ \\
\hline Number of patients & 76 & 76 & ns \\
\hline Sex (female/male) & $37 / 39$ & $32 / 44$ & ns \\
\hline Age, yr & $45 \pm 17$ & $49 \pm 17$ & ns \\
\hline Body weight, kg & $72 \pm 13$ & $82 \pm 19$ & ns \\
\hline Preoperative $\mathrm{Hb}, \mathrm{g} \cdot \mathrm{L}^{-1}$ & $140 \pm 12$ & $141 \pm 15$ & ns \\
\hline ASA score ** & $2(2-2)$ & $2(2-3)$ & $n s$ \\
\hline $\begin{array}{l}\text { Duration of procedure, } \\
\text { min }\end{array}$ & $407 \pm 143$ & $285 \pm 122$ & $<0.000$ \\
\hline $\begin{array}{l}\text { Estimated blood loss, } \\
\text { mL per patient }\end{array}$ & $793 \pm 1083$ & $574 \pm 519$ & 0.114 \\
\hline $\begin{array}{l}\text { Patients transfused } \\
\text { intraoperatively }\end{array}$ & $5 / 76$ & $5 / 76$ & ns \\
\hline $\begin{array}{l}\text { Postoperative } \mathrm{Hb}, \mathrm{g} \cdot \mathrm{L}^{-1} \\
\text { Intraoperative fluid }\end{array}$ & $116 \pm 15$ & $122 \pm 22$ & ns \\
\hline $\begin{array}{l}\text { administration }{ }^{*} \\
\text { Recovery score on arrival }\end{array}$ & $7.4 \pm 3.0$ & $7.7 \pm 3.8$ & ns \\
\hline $\begin{array}{l}\text { in PACU }{ }^{* *} \\
\text { Body temperature in }\end{array}$ & $6(5-7)$ & $6(5-7)$ & $n s$ \\
\hline $\begin{array}{l}\mathrm{PACU},{ }^{\circ} \mathrm{C} \\
\text { Length of stay in }\end{array}$ & $36.7 \pm 0.8$ & $36.4 \pm 0.7$ & $n s$ \\
\hline PACU, min & $100 \pm 43$ & $94 \pm 41$ & ns \\
\hline
\end{tabular}

Mean values \pm standard deviation; ${ }^{*} \mathrm{~mL} \cdot \mathrm{kg}^{-1} \cdot \mathrm{hr}^{-1} ;{ }^{*}$ median value, $25^{\text {th }}-75^{\text {th }}$ percentiles. $i M R I=$ intraoperative magnetic resonance imaging; OR = operating room; PACU = postoperative care unit.

There were no treatment failures (procedures that had to be abandoned or modified) or postoperative infections in either patient group.

\section{Primary end points}

The main finding of the present study was that procedures performed in the MR theatre took approximately two hours (122 min) longer to complete than those done in the conventional OR (Table I). The majority of patients $(57 / 76)$ in the MR theatre had two MR imaging sequences: an initial planning sequence before the surgical incision and an interdissection (prior to wound closure) or quality assurance MR study. Four patients had only an initial scan, 14 patients had surgical planning, interdissection and quality assurance studies, and one patient had four intraoperative studies. From the medical record, the sequence duration could only be determined for the planning and quality assurance (initial and final) scans. The average total time that was devoted to imaging was $101 \pm 29 \mathrm{~min}$. Recorded times for imaging therefore accounted for $83 \%$ of the difference in the length of the procedures between the conventional OR and the MR theatre.
TABLE II Intraoperative monitoring, anesthetic technique and position

\begin{tabular}{|c|c|c|c|}
\hline $\begin{array}{l}\text { Variable } \\
\text { Monitoring }\end{array}$ & iMRI theatre & Conventional OR & $P$ \\
\hline Temperature & 0 & 50 & 0.000 \\
\hline Invasive arterial pressure & 76 & 66 & 0.003 \\
\hline $\begin{array}{l}\text { Invasive central venous } \\
\text { pressure }\end{array}$ & 20 & 17 & 0.698 \\
\hline \multicolumn{4}{|c|}{ Volatile anesthetics and gases } \\
\hline Isoflurane & 75 & 42 & 0.000 \\
\hline Desflurane & 0 & 31 & \\
\hline "awake" craniotomies & 1 & 3 & \\
\hline Nitrous oxide & 75 & 65 & 0.006 \\
\hline \multicolumn{4}{|l|}{ Opioids } \\
\hline Fentanyl & 59 & 44 & 0.026 \\
\hline Sufentanil & 17 & 31 & \\
\hline Morphine & 0 & 1 & \\
\hline \multicolumn{4}{|l|}{ Muscle relaxants } \\
\hline Rocuronium & 61 & 44 & 0.000 \\
\hline Pancuronium & 6 & 8 & \\
\hline Vecuronium & 5 & 1 & \\
\hline No relaxant & 4 & 23 & \\
\hline \multicolumn{4}{|l|}{ Position } \\
\hline Supine & 72 & 61 & 0.000 \\
\hline Lateral & 4 & 10 & \\
\hline Prone/sitting & 0 & $4 / 1$ & \\
\hline
\end{tabular}

The data are presented as the number of patients in each of the treatment or position categories. $P$ values were obtained from Chi square analysis of proportions for single pair comparisons (e.g., nitrous oxide use) or analysis by contingency tables for multiple pair comparisons (e.g., position). $\mathrm{iMRI}=$ intraoperative magnetic resonance imaging; $\mathrm{OR}=$ operating room.

TABLE III Quality of matching of MR theatre and conventional OR

\begin{tabular}{ll}
\hline Match criteria & $\begin{array}{l}\text { Number of successful } \\
\text { matches }\end{array}$ \\
\hline 1 Lesion type (vascular vs tumour) & 76 \\
2 Lesion pathology & 67 \\
3 Lesion location, lobe & 68 \\
4 Lesion location, side & 57 \\
5 Lesion size, within 1 cm largest diameter & 35 \\
\hline
\end{tabular}

$\mathrm{MR}$ = magnetic resonance; $\mathrm{OR}=$ operating room.

\section{Secondary end points}

The increased OR time did not result in delayed emergence from anesthesia as measured by the initial PACU score or the length of stay in PACU (Table I). Estimated blood loss, perioperative transfusion rate, postoperative hemoglobin concentration and intraoperative fluid administration were all similar in the two groups (Table I). Despite the lack of intraoperative tem- 
perature monitoring and active measures to control temperature in patients managed in the MR theatre, initial tympanic membrane temperature on arrival was not different from that of patients managed in the conventional OR where these management modalities were available. (In the conventional OR group, 56/76 patients had temperatures monitored; we could not determine accurately how many patients had active heating/cooling measures applied intraoperatively).

\section{Anesthetic management}

Anesthetic management differed between the two groups in the use of nitrous oxide and in the choices of volatile anesthetics, opioids, and muscle relaxants (Table II). The differences reflect the unavailability of an MR compatible desflurance vaporizer in the iMR OR (isoflurane was the sole volatile anesthetic available for iMRI patients) and personal preferences between the anesthesiologists responsible for the patients. Whereas the majority (>95\%) of anesthetics for cases in the MR theatre were administered by three anesthesiologists, 25 anesthesiologists were involved in the anesthetics delivered in the conventional OR. The differences in anesthetic management (Table II) did not appear to influence the outcomes that we measured. Mannitol, $1 \mathrm{~g} \cdot \mathrm{kg}^{-1}$, and dexamethazone 10 $\mathrm{mg}$, were administered intravenously as a routine for tumour patients immediately following induction of anesthesia. It was also routine before induction of anesthesia to administer an iv dose of a cephalosporin or other appropriate antibiotic.

\section{Discussion}

The results show that it is practical to perform complex neurosurgical procedures in an operating theatre dedicated to intraoperative MR imaging. We found no evidence that the environment required to produce high quality intraoperative MR images resulted in any compromise of anesthetic patient care. The main consequence of iMRI was to prolong the duration of the procedures by $122 \mathrm{~min}$ from $285 \pm 122 \mathrm{~min}$ to $407 \pm$ $143 \mathrm{~min}$. Most $(83 \%)$ of the increased duration was accounted for by the actual imaging time, and could therefore potentially be reduced by altering the imaging sequences themselves. In the only suitable reference that we could find for comparison, Todd $e t a l{ }^{10}$ reported an operative time of $340 \pm 100 \mathrm{~min}$ for elective supratentorial craniotomy performed in a teaching hospital without iMRI. The time reported by Todd $e t$ $a l .{ }^{10}$ was from induction of anesthesia to the beginning of emergence. To make the time correspond to that reported in the present study approximately 15 min preinduction time and 15 min emergence time should be added, making the total approximately 370 min. Thus using the iMRI system described herein, operative times for craniotomy were within $30 \mathrm{~min}$ one hour of operative time previously reported ${ }^{10}$ for supratentorial craniotomy. We could find no evidence that the increased duration of the procedures had any effect on patient recovery, blood loss, or transfusion and fluid requirements. We anticipate that technological developments will soon permit continuous intraoperative temperature monitoring; yet, its absence in the iMRI patients in the present study did not influence PACU arrival temperature.

Previous reports ${ }^{1-3,11-13}$ of brain surgery using intraoperative MRI systems have focussed mainly on the imaging characteristics of the systems - we are not aware of any controlled studies of craniotomy using iMRI. The anesthetic considerations for management of patients in MRI operating theatres have recently been reviewed. ${ }^{5}$ Due to the design of the mobile iMRI theatre, many of the potential hazards of anesthetic administration ascribed to MR $\mathrm{OR}^{5}$ have been avoided. The iMRI theatre is located close (three minutes' walk to the PACU) to the main surgical suite and adjacent to central emergency services and the intensive care unit. The theatre itself is standard size $(7.58 \times$ $10.4 \mathrm{~m}$ ), allowing ample space for anesthetic equipment and easy physical approach to the patient. Patient access during imaging is of course limited by the presence of the magnet, but during surgery the access is the same as in a conventional OR. Using our system, there are no fringe fields during surgery, and even during imaging, fringe fields are reduced by active shielding, reducing the hazards of ferromagnetic objects and making the environment friendlier for monitoring devices.

Limitations of the present study include the retrospective design, which reduced the specificity of the data that we could collect, and the potential differences in surgical and anesthetic management that may have occurred because the latter were not standardized. The lesion characteristics (tumour + edema volume, size, extent of midline shift, and mass effect) could not be matched exactly because preoperative MR images were not available for all patients and these characteristics were frequently not reported. A randomized prospective design would have addressed some of these concerns, but would have had a major drawback: the variety of neurosurgical cases selected would have been severely limited and would not have permitted completion of the study within two years (a reasonable requirement for a safety study). The anesthetic management of the patients was not standardized, and the choice of anesthetic drugs differed 
between the iMRI and conventional OR patients (Table II). Since a randomized clinical trial has previously shown that anesthetic choice for management of craniotomy does not alter anesthetic outcome, ${ }^{10}$ we are not surprised that no differences were detected in the present study. The impact of the potential differences in surgical management would seem to have been small, since imaging time accounted for $83 \%$ of the difference in duration of procedure for the two treatment groups. The present study was not designed to evaluate whether neurosurgical treatment guided by iMRI offers any advantage over conventional treatment or improves patient outcome - to answer these questions will require a randomized clinical trial.

In summary, the present study was designed to evaluate the influence of iMRI perioperative anesthetic management for patients undergoing craniotomy. The results show that the use of an iMRI system in a dedicated OR prolonged the duration of the procedures but had minimal influence on other anesthetic measures of perioperative anesthetic outcome.

\section{Acknowledgements}

The authors thank Drs. T. Kaibara and C. Wallace for their help with database management and radiological review, Mrs. K. Maier for chart review and Mrs. V. Repper for secretarial and photographic assistance.

\section{References}

1 Kaibara T, Saunders JK, Sutherland GR. Advances in mobile intraoperative magnetic resonance imaging. Neurosurgery 2000; 47: 131-8.

2 Sutherland GR, Kaibara T, Louw D, Hoult DI, Tomanek B, Saunders J. A mobile high-field magnetic resonance system for neurosurgery. J Neurosurg 1999; 91: 804-13.

3 Kaibara T, Saunders JK, Sutherland GR. Utility of a moveable 1.5 Tesla intraoperative MR imaging system. Can J Neurol Sci 1999; 26: 313-6.

4 Leblanc P, Aubry B, Gervin M. Moveable intraoperative magnetic resonance imaging systems in the OR. AORN J 1999; 70: 254-67.

5 Manninen PH, Kucharczyk W. A new frontier: magnetic resonance imaging-operating room. J Neurosurg Anesth 2000; 12: 141-8.

6 Turner JM. Anesthesia for Neuroradiology. In: Matta BF, Menon DK, Turner JM (Eds.). Textbook of Neuroanesthesia and Critical Care. London: Greenwich Medical Media Ltd., 2000: 401.

7 Burnstein RM, Menon DK. Anaesthesia for magnetic resonance imaging. In: Matta BF, Menon DK, Turner JM (Eds.). Textbook of Neuroanaesthesia and Critical Care. London: Greenwich Medical Media Ltd., 2000: 411.
8 Bailey JM. Context-sensitive half-times and other decrement times of inhaled anesthetics. Anesth Analg 1997; 85: 681-6.

9 Bailey PL, Egan TD, Stanley TH. Intravenous opioid anesthetics. In: Miller RD (Ed.). Anesthesia, fifth edition. New York: Churchill Livingstone, 2000; 317-20.

10 Todd MM, Warner DS, Sokoll MD, et al. A prospective, comparative trial of three anesthetics for elective supratentorial craniotomy. Propofol/fentanyl, isoflurane/nitrous oxide, and fentanyl/nitrous oxide. Anesthesiology 1993; 78: 1005-20.

11 Bernstein M, Al-Anazi AR, Kucharczyk W, Manninen P, Bronskill M, Henkelman M. Brain tumor surgery with the Toronto open magnetic resonance imaging system: preliminary results for 36 patients and analysis of advantages, disadvantages, and future prospects.

Neurosurgery 2000; 46: 900-9.

12 Black P, Moriarty T, Alexander III E, et al. Development and implementation of intraoperative magnetic resonance imaging and its neurosurgical applications. Neurosurgery 1997; 41: 831-45.

13 Black P, Alexander III E, Martin C, et al. Craniotomy for tumor treatment in an intraoperative magnetic resonance imaging unit. Neurosurgery 1999; 45: 423-33. 